\title{
Integração de cultivares resistentes e fungicidas no controle da mancha de ramulária (Ramularia areola) e produtividade do algodoeiro
}

\author{
Integration of resistant cultivars and fungicides in the control of ramularia leaf spot and yield of cotton
}

\author{
Alfredo Riciere Dias ${ }^{1 *}$ e Gustavo de Faria Theodoro ${ }^{2}$
}

Recebido em 01/09/2016 / Aceito em 07/02/2017

\section{RESUMO}

O algodoeiro é uma das principais espécies cultivadas na região Centro-Oeste do Brasil e há grande utilização de fungicidas para o controle da mancha de ramulária (MR), uma doença de relevante importância econômica causada por Ramularia areola. O objetivo deste trabalho foi avaliar o efeito da integração de cultivares considerados resistentes $(\mathrm{C})$ e tratamentos fungicidas (TF) no controle da MR e produtividade de algodoeiro cultivado em Chapadão do Sul, MS. Foi utilizado o delineamento de blocos ao acaso, com quatro repetições e arranjo fatorial de 3 (C) x 7 (TF). As avaliações consistiram na estimativa da área abaixo do progresso da doença total (AACPDT), na parte inferior (AACPDI) e superior (AACPDS) das plantas. Da mesma forma, estratificou-se a produtividade de algodão em caroço e o índice de micronaire nas fibras. Os dados foram submetidos ao teste $\mathrm{F}$ e as médias comparadas por meio do teste de Scott-Knott a $5 \%$ de probabilidade. Houve interação significativa entre $\mathrm{C} e$ TF para AACPDT, AACPDI e AACPDS, menos para produtividade e índice micronaire. Constatou-se que houve: maior produtividade e severidade da mancha de ramulária na região inferior das plantas; não houve diferença de produtividade entre as cultivares; houve efeito de C e TF no índice de micronaire; e os TF não influenciaram significativamente a severidade nas cultivares FMT 705 e FMT 709, resistentes à MR. Estes resultados recomendam a integração de TF e C para o controle da MR do algodoeiro.

PALAVRAS-CHAVE: controle genético, controle químico, Gossypium hirsutum, Ramularia areola, sustentabilidade.

\section{ABSTRACT}

Cotton is one of the main species grown in the Midwest region of Brazil and there is a high use of fungicides to control Ramularia leaf spot (RLS), an important disease caused by Ramularia areola. The objective of this study was to evaluate the integration of resistant cultivars (C) and fungicides treatments (FT) in the RLS control and yield of cotton grown in Chapadão do Sul, MS, Brazil. The experimental design consisted of randomized blocks with four replications and factorial arrangement of C (3) x FT (7). The whole plant area under the disease curve progress (AUDCPWP) and from the lower (AUDCP-B) and upper (AUDCP-U) half of the plant were all evaluated. Likewise, cotton yield and micronaire index of the fibers were stratified. Obtained data was submitted to the $\mathrm{F}$ test and mean values were compared by the Scott-Knott test at 5\% probability. There was a significant interaction between $\mathrm{C}$ and FT for AUDCPWP, AUDCP-B and AUDCP-U but not for yield and micronaire index. Higher productivity and severity of RLS in the lower half was observed; there was no difference in productivity between cultivars; effect of $\mathrm{C}$ and FT in the micronaire index; and FT had no significant effect on disease severity in the resistant cultivars FMT 705 and FMT 709. These results recommend the integration of $\mathrm{FT}$ and $\mathrm{C}$ to control RLS of cotton.

KEYWORDS: chemical control, genetic control, Gossypium hirsutum, Ramularia areola, sustainability.

${ }^{1}$ Fundação de Apoio à Pesquisa Agropecuária de Chapadão, Chapadão do Sul, MS, Brasil.

${ }^{2}$ Universidade Federal de Mato Grosso do Sul, Campo Grande, MS, Brasil.

*Autor para correspondência <alfredo@fundacaochapadao.com.br> 


\section{INTRODUÇÃO}

O algodoeiro (Gossypium hirsutum L.) destacase como uma das mais importantes culturas agrícolas do Brasil, pelo seu valor econômico e social. Por ser uma cultura que não suporta frio, as condições climáticas que ocorrem na região Centro-Oeste são favoráveis ao seu desenvolvimento (BELTRÃO et al. 2011).

Por outro lado, existem doenças fúngicas que ameaçam economicamente o cultivo do algodoeiro. Entre elas destaca-se a mancha de ramulária, causada por Ramularia areola (sin. Mycosphaerella areola) que é responsável por elevadas perdas de produção na região do cerrado (ANDRADE JUNIOR et al. 2012, MEHTA et al. 2016). SILVA et al. (2010) realizaram um levantamento de doenças na cultura do algodoeiro na região de Chapadão do Sul, MS, durante as safras 2007/08 e 2008/09, e notaram a prevalência da mancha de ramulária, que incidiu em $72,37 \%$ das plantas com capulhos abertos, mesmo havendo aplicações de fungicidas para seu controle.

O desenvolvimento de $R$. areola é favorecido quando as plantas são cultivadas em períodos com noites apresentando alta umidade relativa, com dias secos, e temperaturas oscilando entre 12 a $32{ }^{\circ} \mathrm{C}$ (CURVELO et al. 2010). Segundo ANDRADE JUNIOR et al. (2011), os sintomas se manifestam em ambas as faces da folha, tendo início na face inferior e mostrando um crescimento pulverulento de coloração branca-azulada. Com a evolução dos sintomas, observam-se lesões angulosas entre as nervuras, medindo geralmente de 1 a $3 \mathrm{~mm}$. O aspecto pulverulento é conferido pela esporulação do patógeno e a alta severidade causa desfolha precoce nas plantas (SUASSUNA et al. 2011).

A forma de controle desta doença que é mais utilizada nas regiões cotonicultoras se fundamenta no uso sistemático de fungicidas de poucos grupos químicos, por meio de diversas aplicações durante o desenvolvimento do algodoeiro. Por outro lado, há uma grande preocupação pela pressão de seleção que alguns grupos químicos de fungicidas que são utilizados no algodoeiro exercem sobre patógenos de etiologia fúngica, proporcionando o surgimento de populações resistentes (ISHII \& HOLLOMON 2015). Conforme HOLLOMON (2015), o uso alternado de princípios ativos e o controle integrado de doenças contribui consideravelmente para evitar este problema, pois o cultivo de genótipos resistentes reduz o número de aplicações e, consequentemente, há menor pressão de seleção sobre o patógeno. AQUINO et al. (2008a) indicaram o controle da mancha de ramulária por meio de aplicações de fungicidas protetores, porém, não são empregados no Centro-Oeste brasileiro pelo risco de se perder a ação dos princípios ativos pela ação de chuvas.

Há alguns anos atrás, genes de resistência qualitativa à ramulária foram incorporados nas cultivares FMT 705 e FMT 709 de algodoeiro e disponibilizadas aos cotonicultores (SILVA et al. 2011, CIA et al. 2013, ASCARI et al. 2016). No entanto, CIA et al. (2013) constataram desempenho contraditório de genótipos de algodoeiro em relação à mancha de ramulária em função do local, indicando possível existência de variabilidade genética do agente causal no Brasil. Além de não se saber o comportamento destas cultivares em território sul-mato-grossense, sabe-se que há relutância no uso do controle genético da mancha de ramulária pelos cotonicultores de Mato Grosso do Sul.

O objetivo deste trabalho foi avaliar o efeito da integração de cultivares (C) e tratamentos fungicidas (TF) na severidade da mancha de ramulária e produtividade do algodoeiro na região Nordeste do Estado de Mato Grosso do Sul.

\section{MATERIAL E MÉTODOS}

O experimento foi conduzido durante o ano agrícola 2011/2012, em área experimental localizada no município de Chapadão do Sul, MS, com as seguintes coordenadas geográficas: 184'33" Latitude Sul e 52 $40^{\prime} 45^{\prime \prime}$ de Longitude Oeste e altitude de 810 m. O clima da região, segundo classificação de Köppen, é do tipo Aw, definido como tropical úmido, com estação chuvosa no verão e seca no inverno (KOTTEK et al. 2006). No ano agrícola em que este trabalho foi conduzido, registrou-se $1475 \mathrm{~mm}$ de precipitação, temperatura média anual de $22,1{ }^{\circ} \mathrm{C}$ e umidade relativa do ar oscilando entre $22,9 \%$ e $96,7 \%$ segundo dados coletados em estação meteorológica localizada no local de condução do experimento.

A semeadura foi realizada em sistema de produção convencional em área anteriormente cultivada com algodão, no dia 27 de dezembro de 2011, com semeadora a vácuo, em espaçamento entre linhas de $0,90 \mathrm{~m}$ e a população foi estimada em 90 mil plantas/ha para cada cultivar. A adubação foi realizada de acordo com a exigência da cultura na 
região do cerrado e análise química do solo (SOUZA \& LOBATO 2004).

Foi empregada a cultivar suscetível FMT 701 (testemunha) e as consideradas resistentes, pela instituição que as criou, FMT 705 e FMT 709, todas recomendadas para cultivo na região Centro-Oeste (FUNDAÇÃO MT 2017). O manejo fitossanitário de pragas e plantas daninhas na área experimental foi realizado de maneira semelhante para as três cultivares e seguindo as recomendações disponíveis no Ministério da Agricultura Pecuária e Abastecimento.
$\mathrm{Na}$ Tabela 1, estão descritos os tratamentos fungicidas e os diferentes princípios ativos que foram utilizados neste experimento. A sequência dos ingredientes ativos são os recomendados pelos técnicos da região e os tratamentos variam em função do estádio fenológico e intervalo entre as aplicações.

As parcelas experimentais foram compostas por quatro linhas de algodoeiro, espaçadas em $0,90 \mathrm{~m}$ e com $6,0 \mathrm{~m}$ de comprimento, totalizando $21,6 \mathrm{~m}^{2}$. As aplicações de fungicidas foram realizadas utilizando-se pulverizador costal de pressão constante

Tabela 1. Tratamentos e características dos fungicidas empregados no presente trabalho. Chapadão do Sul, MS, 2013.

Table 1. Treatments and characteristics of the fungicides used in this work. Chapadão do Sul, MS, 2013.

\begin{tabular}{|c|c|c|c|}
\hline Tratamento* & $\begin{array}{c}\text { Concentração } \\
\left(\text { g i.a. } \mathrm{L}^{-1} \mathrm{~kg}^{-1}\right)^{* *}\end{array}$ & $\begin{array}{c}\text { Dose } \\
\left(\mathrm{mL} \text { p.c. } \mathrm{ha}^{-1}\right)^{* * *}\end{array}$ & $\begin{array}{c}\text { Estádio (+dias) no } \\
\text { momento da } \\
\text { aplicação* }^{*}\end{array}$ \\
\hline 1- Testemunha & - & - & - \\
\hline 2- Piraclostrobina+Metconazol & $130+80$ & 500 & V4 \\
\hline >Hidróxido de Fentina & $>400$ & $>500$ & $>\mathrm{V} 4+25$ \\
\hline$>$ Piraclostrobina + Metconazol & $>130+80$ & $>500$ & $>\mathrm{V} 4+50$ \\
\hline >Hidróxido de Fentina & $>400$ & $>500$ & $>\mathrm{V} 4+75$ \\
\hline$>$ Piraclostrobina + Metconazol & $>130+80$ & $>500$ & $>\mathrm{V} 4+100$ \\
\hline 3- Piraclostrobina+Metconazol & $130+80$ & 500 & V4 \\
\hline >Hidróxido de Fentina & $>400$ & $>500$ & $>\mathrm{V} 4+15$ \\
\hline$>$ Piraclostrobina + Metconazol & $>130+80$ & $>500$ & $>\mathrm{V} 4+30$ \\
\hline >Hidróxido de Fentina & $>400$ & $>500$ & $>\mathrm{V} 4+45$ \\
\hline >Piraclostrobina+Metconazol & $>130+80$ & $>500$ & $>\mathrm{V} 4+60$ \\
\hline 4- Piraclostrobina+Metconazol & $130+80$ & 500 & B1 \\
\hline >Hidróxido de Fentina & $>400$ & $>500$ & $>\mathrm{B} 1+25$ \\
\hline$>$ Piraclostrobina + Metconazol & $>130+80$ & $>500$ & $>\mathrm{B} 1+50$ \\
\hline > Hidróxido de Fentina & $>400$ & $>500$ & $>\mathrm{B} 1+75$ \\
\hline$>$ Piraclostrobina+Metconazol & $>130+80$ & $>500$ & $>\mathrm{B} 1+100$ \\
\hline 5- Piraclostrobina+Metconazol & $130+80$ & 500 & B1 \\
\hline >Hidróxido de Fentina & $>400$ & $>500$ & $>\mathrm{B} 1+15$ \\
\hline$>$ Piraclostrobina+Metconazol & $>130+80$ & $>500$ & $>\mathrm{B} 1+30$ \\
\hline >Hidróxido de Fentina & $>400$ & $>500$ & $>\mathrm{B} 1+45$ \\
\hline$>$ Piraclostrobina+Metconazol & $>130+80$ & $>500$ & $>\mathrm{B} 1+60$ \\
\hline 6- Piraclostrobina+Metconazol & $130+80$ & 500 & F1 \\
\hline >Hidróxido de Fentina & $>400$ & $>500$ & $>\mathrm{F} 1+25$ \\
\hline$>$ Piraclostrobina + Metconazol & $>130+80$ & $>500$ & $>\mathrm{F} 1+50$ \\
\hline >Hidróxido de Fentina & $>400$ & $>500$ & $>\mathrm{F} 1+75$ \\
\hline$>$ Piraclostrobina+Metconazol & $>130+80$ & $>500$ & $>\mathrm{F} 1+100$ \\
\hline 7- Piraclostrobina+Metconazol & $130+80$ & 500 & $\mathrm{~F} 1$ \\
\hline >Hidróxido de Fentina & $>400$ & $>500$ & $>\mathrm{F} 1+15$ \\
\hline >Piraclostrobina+Metconazol & $>130+80$ & $>500$ & $>\mathrm{F} 1+30$ \\
\hline >Hidróxido de Fentina & $>400$ & $>500$ & $>\mathrm{F} 1+45$ \\
\hline$>$ Piraclostrobina+Metconazol & $>130+80$ & $>500$ & $>\mathrm{F} 1+60$ \\
\hline
\end{tabular}

$*(>)$ Aplicacão sequencial; **(i.a.) ingrediente ativo; $* * *($ p.c. $)$ produto comercial. 
$\left(\mathrm{CO}_{2}\right)$ equipado com uma barra de $3,0 \mathrm{~m}$, com 6 pontas de jato leque, modelo XR 11002, espaçadas de $0,5 \mathrm{~m}$, pressão de trabalho de 3 bar e volume de calda referente a $150 \mathrm{~L} \mathrm{ha}^{-1}$.

O delineamento utilizado foi de blocos ao acaso, com quatro repetições, em esquema fatorial, sendo que os fatores empregados foram cultivares (três) e tratamentos fungicidas (sete).

Durante todo o desenvolvimento da cultura foi realizado o monitoramento para identificar o momento da primeira detecção de $R$. areola. A etiologia da doença foi feita por meio da observação de conídios típicos do patógeno em folhas com sintomas da doença, por meio do uso de microscópio ótico (BARNETT \& HUNTER 1998).

Foram realizadas avaliações da severidade da mancha de ramulária, utilizando-se escala diagramática proposta por AQUINO et al. (2008b), em 20 folhas escolhidas ao acaso na metade inferior e a mesma quantidade de folhas na metade superior da planta, nas duas linhas centrais da parcela e nos estádios fenológicos F8, F10, F11, F15, C1 e C5 (MARUR \& RUANO 2001). Em seguida, foi determinada a área abaixo da curva de progresso da doença total (AACPDT), na metade inferior (AACPDI) e superior (AACPDS) da planta, conforme CAMPBELL \& MADDEN (1990).

No momento da colheita, no dia 10/09/2012, foi realizada a coleta dos capulhos nas duas linhas centrais de cada parcela, para estimar a produtividade.
Posteriormente, houve o descaroçamento das amostras provenientes da área útil de cada parcela para se determinar a qualidade das fibras por meio do índice micronaire empregando-se o equipamento HVI (High Volume Instrument), em conformidade com BANGE et al. (2010).

Os dados foram submetidos à análise de variância pelo teste $\mathrm{F}$ e as médias comparadas através do teste de Scott-Knott, a 5\% de probabilidade.

\section{RESULTADOS E DISCUSSÃO}

Os primeiros sintomas da mancha de ramulária foram observados nas folhas da região inferior das plantas, aos 79 dias após a emergência das plantas (DAE) das cultivares FMT 701 e FMT 709. Porém, nos algodoeiros cultivar FMT 705 a diagnose da doença ocorreu apenas no $107^{\circ} \mathrm{DAE}$.

As análises de variância se encontram nas Tabelas 2, 3 e 10, onde pode ser observada a interação significativa entre cultivares e os tratamentos fungicidas para AACPDI (Tabela 2).

$\mathrm{Na}$ ausência de controle químico, as cultivares apresentaram reações significativamente diferentes em relação à doença. A FMT 705 apresentou os menores valores de AACPDT, AACPDI e AACPDS, seguida da FMT 709 e da FMT 701 (Tabelas 4, 5 e 6). Considerando-se a AACPDS, o maior progresso da mancha de ramulária foi constatada na cultivar FMT 701, seguido da cultivar FMT 709 e da FMT

Tabela 2. Análise de variância da área abaixo da curva de progresso da mancha de ramulária na parte inferior (AACPDI), superior (AACPDS) e total (AACPDT) das plantas, para cultivares e tratamentos fungicidas. Chapadão do Sul, MS, 2013.

Table 2. Variance analysis of the area under the Ramularia leaf spot progress curve on the lower half (AACPDI), top half (AACPDS) and full plants (AACPDT) for cultivars and fungicide treatments. Chapadão do Sul, MS, 2013.

\begin{tabular}{ccccc}
\hline \multirow{2}{*}{ FV } & \multicolumn{3}{c}{ Teste F } \\
\cline { 2 - 5 } & GL & AACPDI & AACPDS & AACPDT \\
\hline Cultivares (C) & 2 & $449,75^{* *}$ & $392,52^{* *}$ & $481,43^{* *}$ \\
Fungicidas (F) & 6 & $60,68^{* *}$ & $117,91^{* *}$ & $80,74^{* *}$ \\
Interação CxF & 12 & $45,65^{* *}$ & $95,64^{* *}$ & $62,11^{* *}$ \\
\hline Tratamentos & 20 & $90,57^{* *}$ & $132,01^{* *}$ & $109,63^{* *}$ \\
Blocos & 3 & $3,08^{*}$ & $2,28^{\text {ns }}$ & $3,11^{*}$ \\
Resíduo & 60 & - & - & - \\
\hline Total & 83 & - & - & - \\
\hline *significativo a 5\% pelo Teste F; ** significativo a 1\% pelo Teste F; ns não significativo pelo Teste F.
\end{tabular}


Tabela 3. Análise de variância da produtividade de algodão em caroço na metade inferior (Prod.I), superior (Prod.S) e em toda a planta (Prod.T), para cultivares e tratamentos fungicidas. Chapadão do Sul, MS, 2013.

Table 3. Variance analysis of cotton yield in the lower half (Prod.I), top (Prod.S) and full plant (Prod.T) for cultivars and fungicide treatments. Chapadão do Sul, MS, 2013.

\begin{tabular}{lcccc}
\hline \multirow{2}{*}{ FV } & \multicolumn{3}{c}{ Teste F } \\
\cline { 2 - 5 } & GL & Prod.I & Prod.S & Prod.T \\
\hline Cultivares (C) & 2 & $5,18^{* *}$ & $10,45^{* *}$ & $0,28^{\text {ns }}$ \\
Fungicidas (F) & 6 & $4,90^{* *}$ & $3,85^{* *}$ & $6,70^{* *}$ \\
Interação CxF & 12 & $1,09^{\text {ns }}$ & $1,19^{\text {ns }}$ & $1,31^{\text {ns }}$ \\
\hline Tratamentos & 20 & $2,64^{* *}$ & $2,91^{* *}$ & $2,83^{* *}$ \\
Blocos & 3 & $5,54^{* *}$ & $19,15^{* *}$ & $2,72^{\text {ns }}$ \\
Resíduo & 60 & - & - & - \\
\hline Total & 83 & - & - & - \\
\hline *significativo a 5\% pelo Teste F. ${ }^{* *}$ significativo a 1\% pelo Teste F. ${ }^{\text {ns }}$ não significativo pelo Teste F.
\end{tabular}

Tabela 4. Área abaixo da curva de progresso da mancha de ramulária na metade inferior da planta (AACPDI), para cultivares e tratamento fungicidas*. Chapadão do Sul, MS, 2013.

Table 4. Area under the Ramularia leaf spot progress curve in the lower half of the plants (AACPDI) for cultivars and fungicide treatments*. Chapadão do Sul, MS, 2013.

\begin{tabular}{lccccccc}
\hline & \multicolumn{7}{c}{ Tratamento fungicida } \\
\cline { 2 - 8 } Cultivar & & $2-\mathrm{V} 4$ & $3-\mathrm{V} 4$ & $4-\mathrm{B} 1$ & $5-\mathrm{B} 1$ & $6-\mathrm{F} 1$ & $7-\mathrm{F} 1>\mathrm{F} 1+15$ \\
& & $>\mathrm{V} 4+25$ & $>\mathrm{V} 4+15$ & $>\mathrm{B} 1+25$ & $>\mathrm{B} 1+15$ & $>\mathrm{F} 1+25$ & $>\mathrm{F} 1+30$ \\
& & & & \\
& & $>\mathrm{V} 4+50$ & $>\mathrm{V} 4+30$ & $>\mathrm{B} 1+50$ & $>\mathrm{B} 1+30$ & $>\mathrm{F} 1+50$ & $>\mathrm{F} 1+45$ \\
& $>\mathrm{V} 4+75$ & $>\mathrm{V} 4+45$ & $>\mathrm{B} 1+75$ & $>\mathrm{B} 1+45$ & $>\mathrm{F} 1+75$ & $>\mathrm{F} 1+60$ \\
& $>\mathrm{V} 4+100$ & $>\mathrm{V} 4+60$ & $>\mathrm{B} 1+100$ & $>\mathrm{B} 1+60$ & $>\mathrm{F} 1+100$ & \\
\hline FMT 701 & $1082,16 \mathrm{aA}$ & $504,73 \mathrm{aB}$ & $268,17 \mathrm{aC}$ & $322,43 \mathrm{aC}$ & $202,45 \mathrm{aD}$ & $253,45 \mathrm{aC}$ & $167,47 \mathrm{aD}$ \\
FMT 705 & $30,59 \mathrm{cA}$ & $25,49 \mathrm{bA}$ & $22,44 \mathrm{bA}$ & $22,19 \mathrm{bA}$ & $20,06 \mathrm{bA}$ & $22,22 \mathrm{bA}$ & $19,96 \mathrm{bA}$ \\
FMT 709 & $116,71 \mathrm{bA}$ & $57,95 \mathrm{bA}$ & $62,59 \mathrm{bA}$ & $45,10 \mathrm{bA}$ & $43,75 \mathrm{bA}$ & $30,63 \mathrm{bA}$ & $30,28 \mathrm{bA}$
\end{tabular}

*Médias seguidas por letras iguais, minúsculas nas colunas e maiúsculas nas linhas, não diferem entre si pelo teste de Scott-Knott, a 1\% de probabilidade; o coeficiente de variação do tratamento foi 32,67\%.

705 (Tabela 5). Conforme o esperado, constatou-se elevada suscetibilidade da cultivar FMT 701 à mancha de ramulária, que diferiu significativamente das demais cultivares mesmo quando recebeu aplicações de fungicidas.

Todas as cultivares tiveram maiores valores de AACPDI do que AADPDS, e a cultivar FMT 701 apresentou maiores e significativos níveis de severidade da doença no decorrer do tempo em relação às outras cultivares (Tabela 8 ). Percebeu-se ainda que existiram menores AACDPI e AACPDS na FMT 705 em relação à FMT 709. Acredita-se que tanto a FMT
705 quanto a FMT 709 possuem genes de resistência à mancha de ramulária e o atraso no início da doença na cultivar FMT 705 indica a presença de genes que conferem resistência qualitativa (AGRIOS 2005).

Os dados observados para as cultivares consideradas resistentes FMT 705 e FMT 709 estão de acordo com CIA et al. (2013), que relataram que a cultivar FMT 705 mostrou-se resistente a $R$. areola no estado do Mato Grosso. SILVA et al. (2011), avaliando diferentes cultivares de algodoeiro em casa-de-vegetação, constataram os menores índices da área abaixo da curva do progresso de severidade 
da mancha de ramulária nas cultivares FMT 709, IMA CD 05-8276, FMT 705, CNPA GO 2006-174, CNPA 2007-419 inoculadas com isolado de $R$. areola obtido em Goiás. Avaliando a severidade da mancha de ramulária em cultivares de algodão conduzido em duas épocas de semeadura, ASCARI et al. (2016) constataram que a cultivar FMT 705 apresentou menor valor de área abaixo da curva de progresso da doença. Estas observações estão de acordo com GALBIERI et al. (2015), que verificou que isolados de $R$. areola oriundos de Mato Grosso e da Bahia apresentaram dificuldades na produção de conídios sobre a cultivar FMT 705 devido à existência de genes de resistência.

Com relação à produtividade de algodão em caroço da metade inferior e superior das plantas, observou-se que houve diferença significativa dentro dos fatores cultivar e tratamentos fungicidas, no entanto, não existiu interação significativa entre eles. Quanto à produção total de algodão em caroço, houve diferença significativa apenas para o fator TF. Não foi observada, de forma semelhante às outras variáveis, interação significativa entre os fatores (Tabela 3).

Com relação à produtividade de algodão em caroço na metade inferior da planta, não houve interação significativa entre cultivar e tratamentos fungicidas e notou-se que a produtividade das cultivares FMT 701 e FMT 709 foram semelhantes entre si e maiores daquela apresentada pela FMT 705. Plantas desta cultivar apresentaram a maior produtividade de algodão em caroço na metade superior (Tabela 7).
Todas as cultivares produziram mais algodão em caroço na região inferior da planta, porém, a FMT 705 obteve um menor rendimento nesta região. Observou-se que, na metade superior, a cultivar FMT 705 produziu mais que as demais cultivares, todavia, a produtividade de algodão em caroço colhido na planta inteira foi semelhante para as três cultivares avaliadas (Tabela 7).

O comportamento das cultivares em relação à mancha de ramulária influenciou o efeito dos tratamentos fungicidas, sugerindo que deve haver um planejamento de controle químico para cada cultivar (Tabela 2). Não houve efeito dos tratamentos fungicidas para o controle da doença nas cultivares FMT 705 e FMT 709 pois houve pouca severidade da doença no decorrer do tempo na parte inferior das plantas. Por outro lado, a cultivar FMT 701 apresentou o menor progresso da doença quando houve aplicações com intervalos de 15 dias, iniciadas no estádio fenológico B1 e F1 (Tabela 5).

Os tratamentos fungicidas cinco e sete proporcionaram melhor eficácia de controle, pois a intervenção química teve início próximo ao início dos sintomas da doença. Com relação à produtividade na metade inferior da planta, o tratamento com aplicação iniciada no estádio V4 e as demais, com intervalos de 15 dias, não aumentaram o rendimento da cultura (Tabela 7).

O uso de TF para o controle da mancha de ramulária na metade superior da cultivar FMT 701 reduziu significativamente a AACPDS quando as

Tabela 5. Área abaixo da curva de progresso da doença na metade superior da planta (AACPDS) para cultivares e programas de aplicação de fungicida*. Chapadão do Sul, MS, 2013.

Table 5. Area under the Ramularia leaf spot progress curve in the lower half of the plants (AACPDS) for cultivars and fungicide treatments*. Chapadão do Sul, MS, 2013.

\begin{tabular}{|c|c|c|c|c|c|c|c|}
\hline \multirow{6}{*}{ Cultivar } & \multicolumn{7}{|c|}{ Tratamento fungicida } \\
\hline & & $2-\mathrm{V} 4$ & 3-V4 & 4- B1 & 5- B1 & 6- F1 & 7- F1 \\
\hline & & $>\mathrm{V} 4+25$ & $>\mathrm{V} 4+15$ & $>\mathrm{B} 1+25$ & $>\mathrm{B} 1+15$ & $>\mathrm{F} 1+25$ & $>\mathrm{F} 1+15$ \\
\hline & 1- Testemunha & $>\mathrm{V} 4+50$ & $>\mathrm{V} 4+30$ & $>\mathrm{B} 1+50$ & $>\mathrm{B} 1+30$ & $>\mathrm{F} 1+50$ & $>\mathrm{F} 1+30$ \\
\hline & & $>\mathrm{V} 4+75$ & $>\mathrm{V} 4+45$ & $>\mathrm{B} 1+75$ & $>\mathrm{B} 1+45$ & $>\mathrm{F} 1+75$ & $>\mathrm{F} 1+45$ \\
\hline & & $>\mathrm{V} 4+100$ & $>\mathrm{V} 4+60$ & $>\mathrm{B} 1+100$ & $>\mathrm{B} 1+60$ & $>\mathrm{F} 1+100$ & $>\mathrm{F} 1+60$ \\
\hline FMT 701 & $540,68 \mathrm{aA}$ & $88,25 \mathrm{aC}$ & $160,28 \mathrm{aB}$ & $90,49 \mathrm{aC}$ & $75,07 \mathrm{aC}$ & $57,35 \mathrm{aD}$ & $47,36 \mathrm{aD}$ \\
\hline FMT 705 & $20,45 \mathrm{cA}$ & $17,94 \mathrm{bA}$ & $19,16 \mathrm{bA}$ & $16,04 \mathrm{bA}$ & $18,07 \mathrm{bA}$ & $18,04 \mathrm{bA}$ & $16,59 \mathrm{bA}$ \\
\hline FMT709 & $49,97 \mathrm{bA}$ & $23,34 \mathrm{bA}$ & $30,28 \mathrm{bA}$ & $18,68 \mathrm{bA}$ & $22,56 \mathrm{bA}$ & $15,91 \mathrm{bA}$ & $17,72 \mathrm{bA}$ \\
\hline
\end{tabular}

*Médias seguidas por letras iguais, minúsculas nas colunas e maiúsculas nas linhas, não diferem entre si pelo teste de Scott-Knott, a 1\% de probabilidade; o coeficiente de variação do tratamento foi $30,80 \%$. 
aplicações foram iniciadas no estádio F1 e repetidas a 15 ou 25 dias. As plantas das demais cultivares, que não receberam aplicação de fungicidas, apresentaram o mesmo comportamento daquelas que receberam, o que pode ser explicado pela existência de genes de resistência à doença (Tabela 6). Os tratamentos fungicidas 3 e 6 não afetaram a produtividade para a metade superior da planta (Tabela 7).

Por meio dos resultados obtidos neste trabalho, verifica-se que não seria necessário o uso de controle químico para se controlar a mancha de ramulária nas cultivares FMT 705 e FMT 709 (Tabela 6). Porém, é imprescindível garantir que não haja a perda de resistência em genótipos com resistência qualitativa reduzindo-se a pressão de seleção por meio de pelo menos uma aplicação de fungicidas durante o desenvolvimento da planta (HOLLOMON 2015). Na cultivar FMT 701 foi constatada redução significativa no progresso da doença quando foram utilizados os tratamentos fungicidas 5,6 e 7 .

Ao estratificar a evolução da mancha de ramulária na metade inferior e superior das plantas de algodoeiro, independente dos tratamentos, a maior severidade ocorreu na metade inferior por ser uma região que proporciona um ambiente favorável ao desenvolvimento do patógeno e por haver menor probabilidade das gotas dos fungicidas alcançarem adequadamente o alvo. Esta suposição corrobora com autores que estudaram o patossistema Phakopsora packyrhizi x soja (MADALOSSO et al. 2010, LIMA et al. 2012) e Ramularia areola $\mathrm{x}$ algodoeiro (THEODORO et al. 2012, PIZZATO et al. 2013,
PIZZATO et al. 2014, ASCARI et al. 2016). Houve redução significativa da severidade na metade inferior da planta por meio de aplicações iniciando no estádio B1 e seguida por outras com intervalos de 15 dias e quando as aplicações começaram no estádio F1 e com as demais em intervalos de 15 e 25 dias (Tabela 9).

$\mathrm{O}$ único tratamento que não resultou efeito positivo no rendimento total da planta de algodão foi o tratamento fungicida que iniciou as aplicações de fungicidas no estádio V4 e as demais pulverizações repetidas com intervalo de 25 dias. A pressão da doença se deu após o estádio B1 e os tratamentos que foram iniciados na fase vegetativa não foram suficientes para proteger as plantas até o final do ciclo da cultura. Por outro lado, os demais tratamentos proporcionaram uma maior produtividade dos algodoeiros (Tabela 7).

$\mathrm{O}$ fator cultivar apresentou efeito significativo no índice de micronaire na metade inferior da planta, enquanto que não houve efeito do tratamento fungicida e também não existiu interação entre os fatores. $\mathrm{Na}$ metade superior e na planta inteira, houve efeito dos fatores cultivar e tratamento fungicidas, porém não foi constada interação (Tabela 10). Na metade inferior da planta, a cultivar FMT 705 apresentou o maior índice de micronaire, sendo que as cultivares FMT 701 e FMT 709 foram inferiores e não diferiram entre si. Já na metade superior, verificou-se que as cultivares FMT 705 e FMT 709 mostraram elevado índice micronaire na metade superior da planta em relação a cultivar FMT 701 (Tabela 10).

Estas informações corroboram com ROSOLEM (2011), que afirmou que pelo fato de existir muitos

Tabela 6. Área abaixo da curva de progresso da mancha de ramulária na planta total (AACPDT), nas cultivares e programas de aplicação de fungicida*. Chapadão do Sul, MS, 2013.

Table 6. Area under the Ramularia leaf spot progress curve in the full plant (AACPDT) for cultivars and fungicide treatments*. Chapadão do Sul, MS, 2013.

\begin{tabular}{|c|c|c|c|c|c|c|c|}
\hline \multirow{6}{*}{ Cultivar } & \multicolumn{7}{|c|}{ Tratamento fungicida } \\
\hline & \multirow{5}{*}{ 1- Testemunha } & 2- V4 & 3- V4 & 4- B1 & $5-\mathrm{B} 1$ & 6- F1 & 7- F1 \\
\hline & & $>\mathrm{V} 4+25$ & $>\mathrm{V} 4+15$ & $>\mathrm{B} 1+25$ & $>\mathrm{B} 1+15$ & $>\mathrm{F} 1+25$ & $>\mathrm{F} 1+15$ \\
\hline & & $>\mathrm{V} 4+50$ & $>\mathrm{V} 4+30$ & $>\mathrm{B} 1+50$ & $>\mathrm{B} 1+30$ & $>\mathrm{F} 1+50$ & $>\mathrm{F} 1+30$ \\
\hline & & $>V 4+75$ & $>\mathrm{V} 4+45$ & $>\mathrm{B} 1+75$ & $>\mathrm{B} 1+45$ & $>\mathrm{F} 1+75$ & $>\mathrm{F} 1+45$ \\
\hline & & $>\mathrm{V} 4+100$ & $>\mathrm{V} 4+60$ & $>\mathrm{B} 1+100$ & $>\mathrm{B} 1+60$ & $>\mathrm{F} 1+100$ & $>\mathrm{F} 1+60$ \\
\hline FMT 701 & $811,42 \mathrm{aA}$ & $296,49 \mathrm{aB}$ & $214,23 \mathrm{aC}$ & $206,46 \mathrm{aC}$ & $138,76 \mathrm{aD}$ & $155,40 \mathrm{aD}$ & $107,42 \mathrm{aD}$ \\
\hline FMT 705 & $25,52 \mathrm{cA}$ & $21,71 \mathrm{bA}$ & $20,80 \mathrm{bA}$ & $19,11 \mathrm{bA}$ & $19,07 \mathrm{bA}$ & $20,13 \mathrm{bA}$ & $18,27 \mathrm{bA}$ \\
\hline FMT 709 & $83,34 \mathrm{bA}$ & $40,64 \mathrm{bA}$ & $46,43 \mathrm{bA}$ & $31,89 \mathrm{bA}$ & $33,15 \mathrm{bA}$ & $23,27 \mathrm{bA}$ & $24,00 \mathrm{bA}$ \\
\hline
\end{tabular}

*Médias seguidas por letras iguais, minúsculas nas colunas e maiúsculas nas linhas, não diferem entre si pelo teste de Scott-Knott, a 1\% de probabilidade; o coeficiente de variação do tratamento foi 30,49\%. 
Tabela 7. Produtividade de algodão na metade inferior (Prod.I), superior (Prod.S) e na planta inteira (Prod.T), para cultivares e programas de aplicação de fungicida*. Chapadão do Sul, MS, 2013.

Table 7. Cotton yield in lower half (Prod.I), top (Prod.S) and the full plant (Prod.T) for cultivars and fungicide treatments*. Chapadão do Sul, MS, 2013.

\begin{tabular}{|c|c|c|c|}
\hline Fator & Prod. $I^{\mathrm{B}}$ & Prod. $\mathrm{S}^{\mathrm{A}}$ & Prod. $T^{\mathrm{A}}$ \\
\hline \multicolumn{4}{|l|}{ Cultivar } \\
\hline FMT 701 & $112,06 \mathrm{a}$ & $65,34 \mathrm{~b}$ & $177,40 \mathrm{a}$ \\
\hline FMT 705 & $99,11 \mathrm{~b}$ & 82,91 a & $182,02 \mathrm{a}$ \\
\hline FMT 709 & $108,42 \mathrm{a}$ & $72,29 \mathrm{~b}$ & $180,72 \mathrm{a}$ \\
\hline \multicolumn{4}{|l|}{ Tratamento fungicida } \\
\hline 1- Testemunha & $96,04 \mathrm{~b}$ & $63,91 \mathrm{~b}$ & $159,95 \mathrm{~b}$ \\
\hline 2- V4 $>\mathrm{V} 4+25>\mathrm{V} 4+50>\mathrm{V} 4+75>\mathrm{V} 4+100$ & 107,56 a & 77,66 a & $185,23 \mathrm{a}$ \\
\hline $3-\mathrm{V} 4>\mathrm{V} 4+15>\mathrm{V} 4+30>\mathrm{V} 4+45>\mathrm{V} 4+60$ & $91,67 \mathrm{~b}$ & $62,13 \mathrm{~b}$ & $153,81 \mathrm{~b}$ \\
\hline 4- $\mathrm{B} 1>\mathrm{B} 1+25>\mathrm{B} 1+50>\mathrm{B} 1+75>\mathrm{B} 1+100$ & $115,10 \mathrm{a}$ & $75,025 \mathrm{a}$ & $190,13 \mathrm{a}$ \\
\hline $5-\mathrm{B} 1>\mathrm{B} 1+15>\mathrm{B} 1+30>\mathrm{B} 1+45>\mathrm{B} 1+60$ & $109,07 \mathrm{a}$ & 80,997 a & $190,06 \mathrm{a}$ \\
\hline 6- $\mathrm{F} 1>\mathrm{F} 1+25>\mathrm{F} 1+50>\mathrm{F} 1+75>\mathrm{F} 1+100$ & 106,41 a & $71,28 \mathrm{~b}$ & 177,69 a \\
\hline 7- F1 $>\mathrm{F} 1+15>\mathrm{F} 1+30>\mathrm{F} 1+45>\mathrm{F} 1+60$ & 119,87 a & 83,58 a & 203,46 a \\
\hline Coeficiente de Variação & 14,56 & 19,70 & 13,13 \\
\hline
\end{tabular}

*Médias seguidas por letras iguais, minúsculas nas colunas, não diferem entre si pelo teste de Scott-Knott, a $\left({ }^{\mathrm{A}}\right) 1 \%$ de probabilidade e $\left({ }^{\mathrm{B}}\right) 5 \%$ de probabilidade.

Tabela 8. Área abaixo da curva do progresso da mancha de ramulária nas regiões superior (AACPDS) e inferior (AACPDI) de cultivares de algodoeiro. Chapadão do Sul, MS, 2013.

Table 8. Area under the Ramularia leaf spot progress curve in the top (AACPDS) and lower half (AACPDI) of cotton cultivars. Chapadão do Sul, MS, 2013.

\begin{tabular}{ccc}
\hline \multirow{2}{*}{ Cultivar } & \multicolumn{2}{c}{ Severidade } \\
\cline { 2 - 3 } & AACPDI * & AACPDS * \\
\hline FMT 701 & $400,12 \mathrm{aA}$ & $151,36 \mathrm{aB}$ \\
FMT 705 & $23,28 \mathrm{cA}$ & $18,04 \mathrm{bA}$ \\
FMT 709 & $55,29 \mathrm{bA}$ & $25,49 \mathrm{bB}$ \\
\hline CV(\%) & & 36,79
\end{tabular}

*Médias seguidas por letras iguais, minúsculas nas colunas e maiúsculas nas linhas, não diferem entre si pelo teste de Scott-Knott, a 1\% de probabilidade.

frutos se desenvolvendo ao mesmo tempo na planta de algodoeiro, a qualidade física da fibra não é uniforme.

As fibras de algodoeiro da cultivar FMT 705 apresentaram o maior índice de micronaire na planta inteira do que as demais cultivares. Os diferentes TF não apresentaram efeito neste índice nas fibras colhidas na metade inferior da planta. Ao avaliar o índice de micronaire na metade superior e na planta inteira, os tratamentos 4, 6 e 7 proporcionaram os maiores valores, enquanto que os demais tratamentos
(2, 3 e 5) apresentaram menor índice.

Os resultados obtidos por meio deste trabalho permitem afirmar que é possível fazer a integração dos métodos químicos e genéticos no controle da mancha de ramulária do algodoeiro para que haja maior sustentabilidade econômica do sistema de produção e menor impacto ambiental. 
Tabela 9. Área abaixo da curva de progresso da mancha de ramulária na região superior (AACPDS) e inferior (AACPDI) das plantas para os tratamentos fungicida. Chapadão do Sul, MS, 2013.

Table 9. Area under the Ramularia leaf spot progress curve in the top (AACPDS) and lower half (AACPDI) of cotton cultivars for the fungicide treatments. Chapadão do Sul, MS, 2013.

\begin{tabular}{ccc}
\hline \multirow{2}{*}{ Tratamento fungicida } & \multicolumn{2}{c}{ Severidade } \\
\cline { 2 - 3 } $1-$ Testemunha & AACPDI * & AACPDS * \\
\hline 2- $\mathrm{V} 4>\mathrm{V} 4+25>\mathrm{V} 4+50>\mathrm{V} 4+75>\mathrm{V} 4+100$ & $196,06 \mathrm{aA}$ & $203,70 \mathrm{aB}$ \\
$3-\mathrm{V} 4>\mathrm{V} 4+15>\mathrm{V} 4+30>\mathrm{V} 4+45>\mathrm{V} 4+60$ & $117,73 \mathrm{cA}$ & $69,91 \mathrm{bB}$ \\
$4-\mathrm{B} 1>\mathrm{B} 1+25>\mathrm{B} 1+50>\mathrm{B} 1+75>\mathrm{B} 1+100$ & $129,91 \mathrm{cA}$ & $41,74 \mathrm{bB}$ \\
$5-\mathrm{B} 1>\mathrm{B} 1+15>\mathrm{B} 1+30>\mathrm{B} 1+45>\mathrm{B} 1+60$ & $88,75 \mathrm{dA}$ & $38,57 \mathrm{bB}$ \\
$6-\mathrm{F} 1>\mathrm{F} 1+25>\mathrm{F} 1+50>\mathrm{F} 1+75>\mathrm{F} 1+100$ & $102,10 \mathrm{dA}$ & $30,43 \mathrm{bB}$ \\
$7-\mathrm{F} 1>\mathrm{F} 1+15>\mathrm{F} 1+30>\mathrm{F} 1+45>\mathrm{F} 1+60$ & $72,57 \mathrm{dA}$ & $27,22 \mathrm{bB}$ \\
\hline $\mathrm{CV}(\%)$ & & 36,79
\end{tabular}

*Médias seguidas por letras iguais, minúsculas nas colunas e maiúscula nas linhas, não diferem entre si pelo teste de Scott-Knott, a 1\% de probabilidade.

Tabela 10. Índice de micronaire da fibra na metade inferior (Mic.I), superior (Mic.S) e em toda a planta (Mic.T), para cultivares e tratamentos fungicidas. Chapadão do Sul, MS, 2013.

Table 10. Micronaire fiber index in the lower half (Mic.I), top (Mic.S) and full plants (Mic.T) for cultivars and fungicide treatments. Chapadão do Sul, MS, 2013.

\begin{tabular}{cccc}
\hline Cultivar & Mic.I & Mic.S & Mic.T \\
\hline FMT 701 & $3,92 \mathrm{~b}$ & $3,69 \mathrm{~b}$ & $3,80 \mathrm{~b}$ \\
FMT 705 & $4,22 \mathrm{a}$ & $4,05 \mathrm{a}$ & $4,14 \mathrm{a}$ \\
FMT 709 & $3,89 \mathrm{~b}$ & $3,95 \mathrm{a}$ & $3,92 \mathrm{~b}$ \\
\hline Tratamento fungicida *** & & $3,70 \mathrm{~b}$ & $3,82 \mathrm{~b}$ \\
1- Testemunha & $3,94 \mathrm{a}$ & $3,84 \mathrm{~b}$ & $3,91 \mathrm{~b}$ \\
2- V4 $>\mathrm{V} 4+25>\mathrm{V} 4+50>\mathrm{V} 4+75>\mathrm{V} 4+100$ & $3,98 \mathrm{a}$ & $3,63 \mathrm{~b}$ & $3,74 \mathrm{~b}$ \\
3- V4 $>\mathrm{V} 4+15>\mathrm{V} 4+30>\mathrm{V} 4+45>\mathrm{V} 4+60$ & $3,85 \mathrm{a}$ & $3,99 \mathrm{a}$ & $4,01 \mathrm{a}$ \\
4- B1 $>\mathrm{B} 1+25>\mathrm{B} 1+50>\mathrm{B} 1+75>\mathrm{B} 1+100$ & $4,04 \mathrm{a}$ & $3,86 \mathrm{~b}$ & $3,93 \mathrm{~b}$ \\
$5-\mathrm{B} 1>\mathrm{B} 1+15>\mathrm{B} 1+30>\mathrm{B} 1+45>\mathrm{B} 1+60$ & $3,99 \mathrm{a}$ & $4,13 \mathrm{a}$ & $4,14 \mathrm{a}$ \\
6- F1 $>\mathrm{F} 1+25>\mathrm{F} 1+50>\mathrm{F} 1+75>\mathrm{F} 1+100$ & $4,14 \mathrm{a}$ & $4,13 \mathrm{a}$ & $4,13 \mathrm{a}$ \\
\hline 7- F1 $>\mathrm{F} 1+15>\mathrm{F} 1+30>\mathrm{F} 1+45>\mathrm{F} 1+60$ & $4,14 \mathrm{a}$ & $9,43^{* *}$ & $13,03^{* *}$ \\
\hline Cultivares $(\mathrm{C})$ & $16,23^{* *}$ & $4,38^{* *}$ & $4,33^{* *}$ \\
\hline Programa $(\mathrm{P})$ & $2,21^{\text {ns }}$ & $0,67^{\text {ns }}$ & $0,43^{\text {ns }}$ \\
\hline Interação CxP & $1,19^{\text {ns }}$ & 8,31 & 6,26
\end{tabular}

**significativo a $1 \%$ pelo Teste $\mathrm{F} .{ }^{\text {ns }}$ não significativo pelo Teste $\mathrm{F} . * * *(V 4)$ Período vegetativo com quatro folhas que tenham o comprimento de $2,5 \mathrm{~cm}$ de nervura principal. (B1) Início da fase reprodutiva, primeiro botão floral visível. (F1) Primeira flor no primeiro ramo frutífero. 


\section{CONCLUSÃO}

Notou-se interação significativa entre cultivares e tratamentos fungicidas para AACPDT, AACPDI e AACPDS, menos para produtividade e micronaire.

Os tratamentos fungicidas não tiveram efeito significativo na severidade da doença nas cultivares FMT 705 e FMT 709.

\section{REFERÊNCIAS}

AGRIOS GN. 2005. Plant pathology. 5th ed. San Diego: Elsevier Elsevier Academic Press. 922p.

ANDRADE JUNIOR E et al. 2012. Mancha de ramularia em algodão. Revista Cultivar Grandes Culturas 153: 12-13. ANDRADE JUNIOR ER et al. 2011. Avaliação de manejo de fungicidas no controle de Ramularia (Ramularia areola) no algodoeiro em Campo Verde-MT. In: 8 Congresso Brasileiro de Algodão. Anais.... Campina Grande: Embrapa Algodão. p.321-327.

AQUINO LA et al. 2008a. Controle alternativo da mancha de ramularia do algodoeiro. Summa Phytopathologica 34: 131-136.

AQUINO LA et al. 2008b. Elaboração e validação de escala diagramática para quantificação da mancha de ramularia do algodoeiro. Summa Phytopathologica 34: 361-363.

ASCARI JP et al. 2016. Severity of ramularia leaf spot and seed cotton yield in different sowing times. Revista Caatinga 29: 603-610.

BANGE MP et al. 2010. A method to estimate the effects of temperature on cotton micronaire. The Journal of Cotton Science 14: 164-172.

BARNETT HL \& HUNTER BB. 1998. Illustrated genera of imperfect fungi. St. Paul: APS Press. 218p.

BELTRÃO NE de $\mathrm{M}$ et al. 2011. Zoneamento agroclimático do algodoeiro no cerrado brasileiro. In: FREIRE EC. Algodão no cerrado do Brasil. Aparecida de Goiânia: ABRAPA. p.239-256.

CAMPBELL CL \& MADDEN LV. 1990. Introduction to plant disease epidemiology. New York: Wiley. 532p.

CIA E et al. 2013. Reação de genótipos de algodoeiro à mancha de Ramularia em diferentes épocas e ambientes. Summa Phytopathologica 39: 193-197.

CURVELO CRS et al. 2010. Microscopia eletrônica de varredura do processo infeccioso de Ramularia areola em folhas de algodoeiro. Tropical Plant Pathology 35: 108-113. FUNDAÇÃO MT. 2017. Disponível em: http://www. fundacaomt.com.br/. Acesso em: 10 jan. 2016.

GALBIERI $\mathrm{R}$ et al. 2015. Ramularia areola sporulation potential in Brazilian cotton. Summa Phytopathologica 41: 233-235.

HOLLOMON DW. 2015. Fungicide resistance: facing the challenge. Plant Protection Science 51: 170-176.

ISHII H \& HOLLOMON DW. 2015. Fungicide resistance in plant pathogens: principles and a guide to practical management. Tokyo: Spriger. 489p.

KOTTEK M et al. 2006. World Map of the Köppen-Geiger climate classification updated. Meteorologische Zeitschrift 15: 259-263.

LIMA SF et al. 2012. Efeito da semeadura em linhas cruzadas sobre a produtividade de grãos e a severidade da ferrugem asiática da soja. Bioscience Journal 28: 954-962. MADALOSSO MG et al. 2010. Cultivares, espaçamento entrelinhas e programas de aplicação de fungicidas no controle de Phakopsora pachyrhizi Sidow em soja. Ciência Rural 40: 2256-2261.

MARUR CJ \& RUANO O. 2001. A reference system for determination of developmental stages of upland cotton. Revista Brasileira de Oleaginosas e Fibrosas 5: 313-317.

MEHTA YR et al. 2016. Mycosphaerella areola - The teleomorph of Ramularia areola of cotton in Brazil, and its epidemiological significance. American Journal of Plant Sciences 7: 1415-1422.

PIZZATO JA et al. 2013. Epidemiologic study of Ramularia areola under different soil covers and spacings, for cotton crops. American Journal of Plant Sciences 4: 2049-2059. PIZZATO JA et al. 2014. Geostatistics as a methodology for studying the spatiotemporal dynamics of Ramularia areola in cotton crops. American Journal of Plant Sciences 5: 2472-2479.

ROSOLEM AC. 2011. Ecofisiologia do algodoeiro: implicações na época de semeadura e qualidade. In: FREIRE EC et al. Algodão no Cerrado do Brasil. Aparecida de Goiânia: ABRAPA. p.753-776.

SILVA JC et al. 2011. Avaliação do comportamento de cultivares de algodoeiro à mancha de ramularia. In: 8 Congresso Brasileiro de Algodão. Anais.... Campina Grande: Embrapa Algodão. p.336-341.

SILVA RR et al. 2010. Avaliação da incidência de doenças em algodoeiros cultivados na região de Chapadão do Sul. Revista Brasileira de Oleaginosas e Fibrosas 14: 91-95.

SOUZA DMG \& LOBATO E. 2004. Cerrado: correção do solo e adubação. Brasília: Embrapa Cerrados. 416p.

SUASSUNA ND et al. 2008. Manejo de doenças do algodoeiro. In: BELTRÃO NE de M \& AZEVEDO DMP de. (Ed.). O Agronegócio do Algodão no Brasil. Brasília: Embrapa Informação Tecnológica. p.983-1032.

THEODORO GF et al. 2012. Espaçamento e doenças. Cultivar Grandes Culturas 14: 26-28. 